\title{
Fitur Seleksi Untuk Optimalisasi Kinerja Asisten Dosen
}

\author{
Rizal Prasetyo \\ Sekolah Tinggi Manajemen Informatika dan Komputer Nusa Mandiri \\ e-mail:14002272@nusamandiri.ac.id
}

\begin{abstract}
Lecturers and assistants can help improve the quality of education if both are not present, the student gets a loss, therefore a teaching assistant needs to be improved with one of the methods including the decision tree method. Decision tree can produce a very simple decision, but the decision tree method needs to be optimized in its performance and therefore needs to use optimization methods, one of them is the particle swarm optimization method. Particle swarm optimization is an optimization method by removing and selecting excessive features to produce optimal accuracy. From the results of this study using the decision tree method, an accuracy of $60.26 \%$ is obtained. However, the presence of features selected by particle swarm optimization can increase accuracy by $67.54 \%$ and prove that the optimization of particle swarm optimization can increase by $07.28 \%$. And our results prove that the particle swarm optimization method can improve accuracy by selecting existing features so that the performance of the teaching assistant can improve the quality of education in the future..
\end{abstract}

Keywords: Decision Tree, Feature Selection, Optimization of Lecturer Assistant Performance, Particle Swarm Optimization.

\section{PENDAHULUAN}

Pendidikan sangat penting untuk membangun pemikiran sumber daya manusia dengan meningkatkan kualitas pendidikan tinggi dalam pengajaran diperlukan adanya seorang pengajar atau dosen. Akan tetapi jika tidak adanya seorang pengajar atau dosen akan membuat siswa mendapatkan kerugian dalam menuntut ilmu. Oleh karena itu setiap kampus selalu menerima seorang asisten dosen untuk membantu seorang dosen jika berhalangan dalam mengajar. Asisten dosen yang membantu untuk melakukan tugas mengajar atau layanan dasar untuk mahasiswa dengan memberikan informasi pelajaran yang diberikan oleh seorang dosen, ketika dosen tersebut tidak hadir atau sedang ada pekerjaan lain. Seorang asisten dosen sangat penting untuk menerapkan model dan metode pengajaran yang tepat sesuai dengan isi dan objek pengajaran yang ditentukan. Pada saat yang sama, penting untuk mengintegrasikan beberapa metode pengajaran baik pengajaran modern maupun pengajaran tradisional. Dalam pengajaran modern, model pengajaran tradisional terancam oleh caracara terbatas, model pengajaran modern dengan mempopulerkan aplikasi komputer, pengeluaran sumber internet dan cara yang lain dalam tahap belajar dapat meningkatkan pengetahuan mahasiswa. Dalam hal pengajaran seorang asisten dosen perlu di optmalisasi kinerjanya maka dibutuhkan sebuah metode dan salah satunya metode decission tree.

Dalam penelitian asisten dosen metode decision tree sudah pernah dilakukan dengan 22 metode algoritma decision tree dimana dalam penelitian ini menggunakan 32 dataset dan menghasilkan algoritma quest yang mendapatkan akurasi tertinggi (Lim, Loh, \& Shih, 2000). Pada penelitian lain pernah dilakukan dengan metode neural network dengan optimalisasi particle swarm optimization (Ariyati, Ridwansyah, \& Suhardjono, 2018) dan dengan data set yang sama pernah dilakukan evaluasi kinerja asisten dosen dengan metode neural network berbasis co-evolusioner (Ridwansyah, Ariyati, \& Faizah, 2018). Akan tetapi kami tidak menggunakan neural network dikarenakan neural network lemah terhadap data noise yang akan mengakibatkan ketidak stabilan dalam memprediksi (Dimopoulos, Tsiros, Serelis, \& Chronopoulou, 2004), dari kelemahan neural network tersebut penelitian ini menggunakan metode Decission Tree. Algoritma yang popular dengan tingkat ke 10 merupakan algoritma decision tree (Han \& Kamber, 2006).

Algoritma decision tree dengan menghasilkan sebuah pohon keputusan dari data dengan aturanaturan atau rule dengan klasifikasi nilai atribut menjadi class dan akan menghasilkan klasifikasi baru (Wu \& Kumar, 2009). Decission tree dalam pengambilan keputusan yang rumit dapat diubah menjadi kuputsan yang sederhana(Sugianto, 2015), Decission tree juga mudah untuk data yang relatif kecil dan dapat dimengerti (Gorunescu, 2011).

Untuk menghasilkan akurasi yang optimal diperlukan metode optimasi untuk decision tree. Metode optimasi yang digunakan untuk menseleksi fitur-fitur yang berlebih yaitu dengan menggunakan metode particle swarm optimization (PSO). Dalam proses pemilihan fitur secara optimal dapat dilakukan dengan menghilangkan fitur yang tidak relevan dalam kinerja asisten dosen (Xu, Peng, \& Cheng, 2012). Dengan dilakukan penghilangan fitur yang berlebih maka dapat meningkatkan akurasi (Cao, Cui, Shi, \& Jiao, 2016). Penelitian yang dilakukan untuk optimasi pernah dilakukan dengan kombinasi dua puluh parameter dan mendapatkan hasil akurasi $95.69 \%$ yang dapat meningkatkan 
akurasi dalam memprediksi (Ridwansyah \& Purwaningsih, 2018).

Dari penelitian yang sudah dilakukan peneliti sebelumnya dapat disimpulkan bahwa particle swarm optimization sangat baik untuk memprediksi kelulusan mahasiswa.

\section{METODOLOGI PENELITIAN}

Pada metodologi penelitian ini dijelaskan mengenai metode DT dan PSO yang akan dilakukan uji coba dengan data kelulusan mahasiswa. Diagram yang ada menunjukan bagaimana proses metodologi penelitian yang dibuat untuk mencari hasil dari data yang kita olah. Berikut aktifiti diagram dengan metode DT dan PSO.

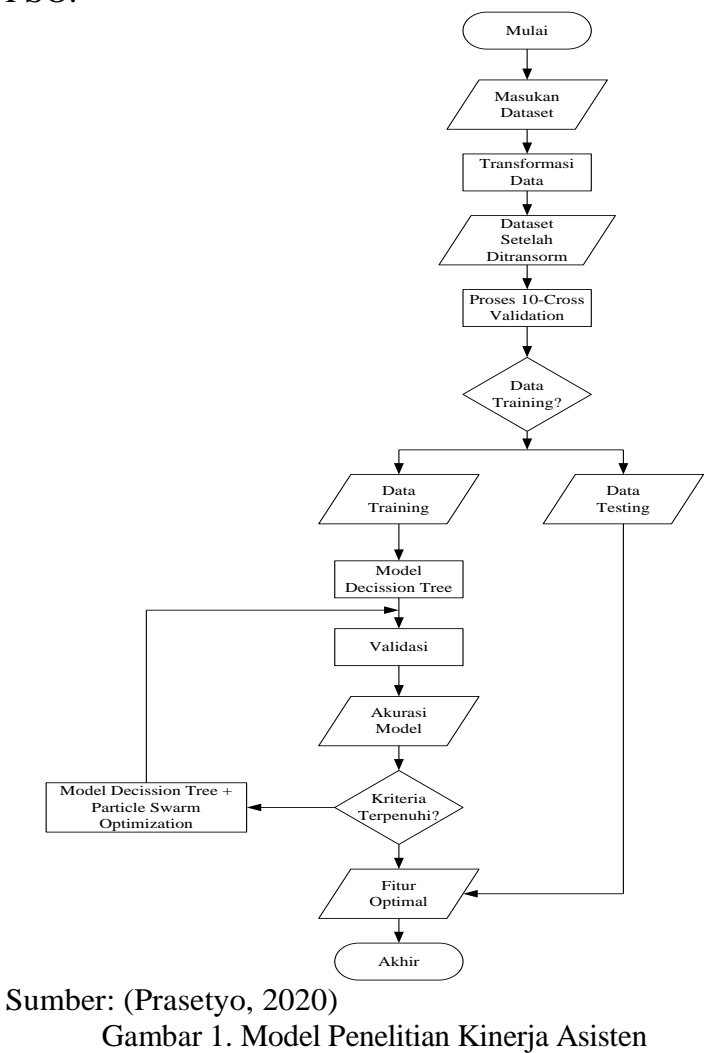

Dari pertama kali yang dilakukan dengan memasukan dataset kelulusan mahasiswa dari data tersebut yang telah dilakukan pre-processing akan ditransformasi sehingga menghasilkan data yang telah di transformasikan dengan menggunakan 10cross validation. Setelah data dilakukan transformasi maka akan dilakukan data training dan data testing, jika data training dilakukan maka menggunakan model decision tree dengan memvalidasi data yang ada dan mendapatkan akurasi model. Jika hasil kriteria model terpenuhi maka didapatkan fitur yang optimal untuk mendapatkan fitur yang terbaik, jika kriteria model tidak memenuhi maka akan dilakukan uji coba dengan menggunakan decision tree (DT) dengan seleksi fitur menggunakan particle swarm optimization (PSO) sampai mendapatkan hasil fitur yang optimal.

\section{Pengumpulan Dan Pengolahan Data}

Kami mengumpulkan dan mendapatkan dataset dari UCI Machine Learning Repository. Dari data yang dikumpulkan terdapat seribu enam ratus tiga puluh delapan empat (151) data. Dengan data yang dapat dilihat Pada tabe 11 .

Tabel 1. Infromasi Atribut

\begin{tabular}{|l|l|}
\hline Atribut & Keterangan \\
\hline English Speaker & $\begin{array}{l}\text { 1=English speaker, 2=non- } \\
\text { English speaker }\end{array}$ \\
\hline Course Instructor & categorical, 25 categories \\
\hline Course & categorical, 26 categories \\
\hline Semester & 1=Summer, 2=Regular \\
\hline Class Size & numerical \\
\hline
\end{tabular}

Sumber: Uci Repositori

Dari data yang terlihat pada tabel 1 dengan tindak lanjut yaitu melakukan normalisasi data dan transformasi data dengan mengusulkan dan menerapkan decision tree dan pengoptimalan dengan particle swarm optimization.

\section{HASIL DAN PEMBAHASAN}

Penelitian yang kami lakukan dengan menggunakan komputer dengan spesifikasi CPU Intel Core i7 1.6GHz, RAM 16GB, dan sistem operasi Microsoft Windows 10 64-bit. Aplikasi yang digunakan adalah RapidMiner 9.3. Penelitian ini menggunakan dataset yaitu dataset teacher asistant. Dataset yang diperoleh dari sebuah web yang menyimpan data secara globa yaitu UCI Machine Learning Repository.

Data kelulusan mahasiswa digunakan untuk mengetahui apakah fitur kelulusan mahasiswadapat lulus tepat waktu atau tidak. Pegukuran penelitian ini menggunakan rapid miner 9.3 dengan aktifiti diagram yang dilakukan maka dapat dilihat hasil dari metode DT dan DT berbasis PSO.

1. Decission Tree

Setelah dilakukan dengan model DT maka didapatkan hasil confussion matrix yang dilihat pada tabel 2 .

Tabel 2. Confussion Matrix Kinerja Asisten Dosen Model Decission Tree

\begin{tabular}{lccc}
\hline Keterangan & True High & $\begin{array}{c}\text { True } \\
\text { Low }\end{array}$ & $\begin{array}{c}\text { Class } \\
\text { Precission }\end{array}$ \\
\hline Prediksi High & 44 & 26 & $62.86 \%$ \\
\hline Rrediksi Low & 34 & 47 & $58.02 \%$ \\
\hline Class Recall & $56.41 \%$ & $64.38 \%$ & \\
\hline
\end{tabular}

Sumber: (Prasetyo, 2020)

Untuk mendapatkan akurasi dari confussion matrix dapat di hitung dengan rumus dibawah ini

$$
\begin{gathered}
\text { Akurasi }=\frac{(\mathrm{TN}+\mathrm{TP})}{(\mathrm{TN}+\mathrm{FN}+\mathrm{TP}+\mathrm{FP})} \\
\text { Akurasi }=\frac{(44+47)}{(44+34+47+26)}=0,602649
\end{gathered}
$$

Dengan rumus akurasi diatas dapat dilihat bahwa akurasi dengan model decisission tree sebesar 
0.602649 atau dipindahkan dengan nilai persen sebesar $60.26 \%$. Dari keterangan yang terlihat pada table 2 menyatakan bahwa asisten yang diprediksi tinggi kinerjanya sebesar 44 akan tetapi dengan jumlah 34 yang di prediksi tinggi mendapatkan kesalahan prediksi dan menjadi prediksi rendah. Untuk prediksi asisten dengan nilai yang rendah sebesar 26 ternyata mendapatkan hasil prediksi tinggi. Untuk asisten yang diprediksi rendah 47 dan benar hasil diprediksinya. Dari hasil prediksi tersebut dapat digambarkan dengan diagram batang yang tertera di bawah ini.

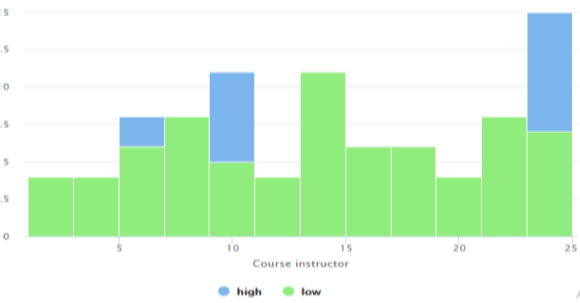

Sumber (Prasetyo, 2020)

Gambar 2. Diagram Batang Kinerja Assiten

Dari akurasi yang didapatkan untuk kinerja asisten dengan model decision tree maka didapatkan area under curve(AUC) yang dapat dilihat dari gambar 3.

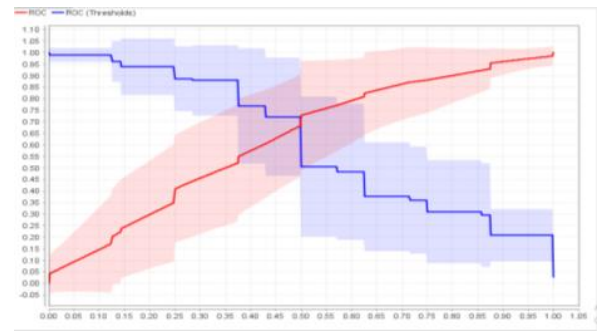

Sumber: (Prasetyo, 2020)

Gambar 3. Diagram AUC Kinerja Assiten

Dari hasil pengujian dengan decision tree maka didapatkan rule algoritma kinerja asisten yang dapat dilihat pada gambar 4 .

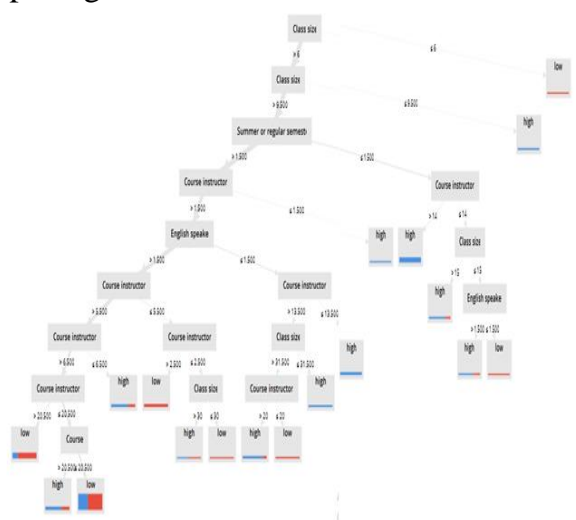

Sumber: (Prasetyo, 2020)

Gambar 4. Arsitektur Decision Tree Kinerja Assiten

2. Decission Tree dengan Particle Swarm Optimization

Setelah di uji coba menggunakan decision tree maka akan di optimasi menggunakan particle swarm optimization. Dari hasil yang didapat dengan menggunakan optimasi PSO maka didapatkan bobot atribut dan confussion matrix yang dapat dilihat pada table 3 dan table 4 .

Tabel 3. Bobot atribut metode decision tree dan particle swarm optimization

\begin{tabular}{|l|l|}
\hline Atribut & Bobot \\
\hline English speaker & 1 \\
\hline Course instructor & 1 \\
\hline Course & 0.40583551730458783 \\
\hline Summer or regular semester & 0.6001391343214106 \\
\hline Class size & 0.2885892191132615 \\
\hline
\end{tabular}

Sumber: (Prasetyo, 2020)

Dari tabel bobot tersebut menerangkan bahwa atribut yang tinggi nilai bobotnya adalah atribut English speaker dan course instructor yang mendapatkan nilai 1 dan mendapatkan bahwa atribut tersebut mendapati atribut yang maksimal.

Tabel 4. Confussion Matrix Kinerja Asisten Dosen Model Decission Tree + Particle Swarm Optimization

\begin{tabular}{lccc}
\hline Keterangan & True High & True Low & $\begin{array}{c}\text { Class } \\
\text { Precission }\end{array}$ \\
\hline Prediksi High & 46 & 17 & $73.02 \%$ \\
\hline Rrediksi Low & 32 & 56 & $63.64 \%$ \\
\hline Class Recall & $58.97 \%$ & $76.71 \%$ & \\
\hline
\end{tabular}

Sumber: (Prasetyo, 2020)

Untuk mendapatkan akurasi dari confussion matrix dapat di hitung dengan rumus dibawah ini.

$$
\begin{gathered}
\text { Akurasi }=\frac{(\mathrm{TN}+\mathrm{TP})}{(\mathrm{TN}+\mathrm{FN}+\mathrm{TP}+\mathrm{FP})} \\
\text { Akurasi }=\frac{(46+56)}{(46+32+56+17)}=0,675497
\end{gathered}
$$

Dengan rumus akurasi diatas dapat dilihat bahwa akurasi dengan model decisission tree sebesar 0.675497 atau dipindahkan dengan nilai persen sebesar $67.54 \%$. Dari keterangan yang terlihat pada table 3 menyatakan bahwa asisten yang diprediksi tinggi kinerjanya sebesar 46 akan tetapi dengan jumlah 32 yang di prediksi tinggi mendapatkan kesalahan prediksi dan menjadi prediksi rendah. Untuk prediksi asisten dengan nilai yang rendah sebesar 17 ternyata mendapatkan hasil prediksi tinggi. Untuk asisten yang diprediksi rendah 56 dan benar hasil diprediksinya. Dari hasil prediksi tersebut dapat digambarkan dengan diagram batang yang tertera di bawah ini.

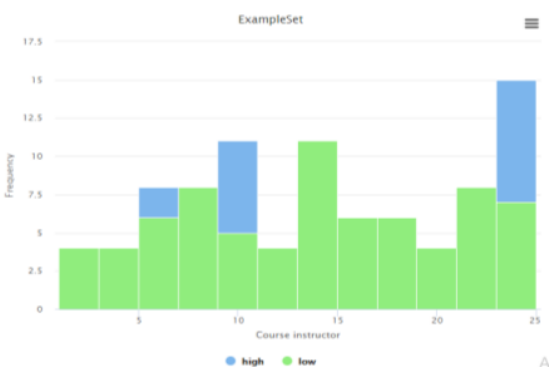

Sumber: (Prasetyo, 2020)

Gambar 5. Diagram Batang Kinerja Assiten Optimasi PSO 
Dari akurasi yang didapatkan untuk kinerja asisten dengan model decision tree optimasi particle swarm optimization maka didapatkan area under curve (AUC) yang dapat dilihat dari gambar 6 .

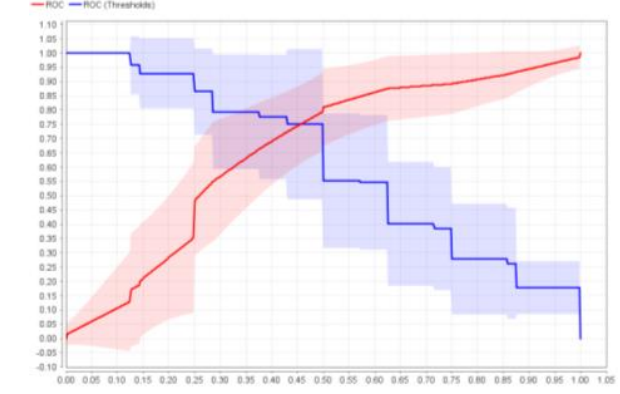

Sumber: (Prasetyo, 2020)

Gambar 6. Diagram AUC Kinerja Assiten Optimasi PSO

Dari hasil pengujian dengan optimasi particle swarm optimization maka didapatkan rule algoritma kinerja asisten yang dapat dilihat pada gambar 7 .

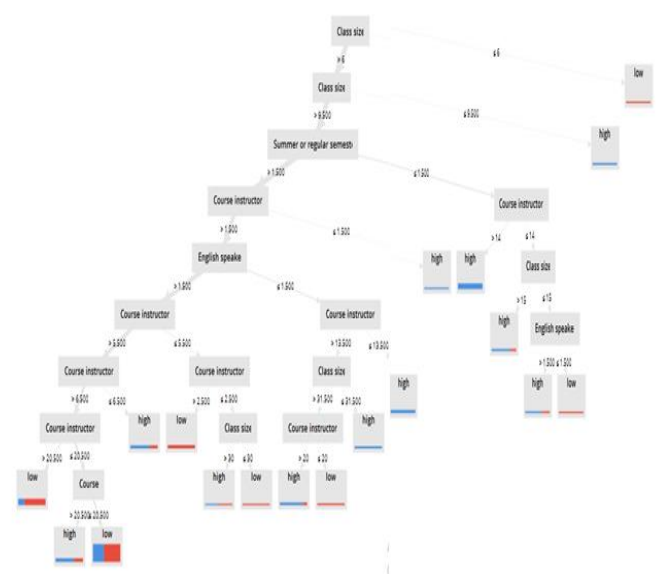

Sumber: Prasetyo (2020)

Gambar 7. Arsitektur Optimasi Kinerja Assiten dengan PSO

\section{KESIMPULAN}

Kinerja asisten dosen setelah kami melakukan uji coba terhadap kinerjanya dalam mengajar terhadap mahasiswa menunjukkan hasil yang lebih baik dengan proses evaluasi kinerja asisten dosen dan mendapatkan hasil yang akurat atas kinerja asisten dosen dengan kombinasi lima parameter penelitian pada dataset asisten dosen dengan decision tree dan particle swarm optimization.

Dari hasil yang dilakukan dalam penelitian ini dengan menggunakan metode decision tree maka didapatkan akurasi sebesar 60.26\%. Akan tetapi dengan adanya fitur yang diseleksi dengan particle swarm optimization dapat meningkatkan akurasi sebesar $67.54 \%$ dan membuktikan dengan adanya optimasi particle swarm optimization dapat meningkatkan sebesar $07.28 \%$. Metode particle swarm optimization dapat meningkatkan akurasi metode decision tree dengan menseleksi fitur, sehingga fitur yang dihasilkan akan berbobot.

Dari hasil model yang diusulkan algoritma PSO terhadap decision tree dengan hasil nilai akurasi tertinggi dapat digunakan sebagai acuan untuk menilai kinerja asisten dosen secara berkala dengan fitur yang optimal.

\section{REFERENSI}

Ariyati, I., Ridwansyah, \& Suhardjono. (2018). Implementasi Particle Swarm Optimization untuk Optimalisasi Data Mining Dalam Evaluasi Kinerja Asisten Dosen. JIKO (Jurnal Informatika Dan Komputer) STMIK AKAKOM, 3(2), 70-75.

Cao, J., Cui, H., Shi, H., \& Jiao, L. (2016). Big data: A parallel particle swarm optimization-backpropagation neural network algorithm based on MapReduce. PLoS ONE, 11(6), 1-17.

Dimopoulos, L. F., Tsiros, L. X., Serelis, K., \& Chronopoulou, A. (2004). Combining Neural Network Models to Predict Spatial Patterns of Airborne Pollutant Accumulation in Soils around an Industrial Point Emission Source. Journal of the Air \& Waste Management Association, 54(12), 1506-1515.

Gorunescu, F. (2011). Data Mining: Concepts, Models and Technique.

Han, J., \& Kamber, M. (2006). Data Mining Concept and Techniques. India: New Age International Limited.

Lim, T. S., Loh, W. Y., \& Shih, Y. S. (2000). A comparison of prediction accuracy, complexity, and training time of thirty-three old and new classification algorithms. Mach. Learn, 40(3), 203-228.

Prasetyo, R. (2020). Fitur Seleksi Untuk Optimalisasi Kinerja Asisten Dosen. jakarta.

Ridwansyah, Ariyati, I., \& Faizah, S. (2018). Particle Swarm Optimization Berbasis CoEvolusioner. Jurnal SAINTEKOM, 9(2), 166$177 . \quad$ Retrieved from http://stmikplk.ac.id/jurnal/index.php/sainteko $\mathrm{m} /$ article/view/96/62

Ridwansyah, \& Purwaningsih, E. (2018). Particle Swarm Optimization Untuk Meningkatkan Akurasi Prediksi Pemasaran Bank. Jurnal PILAR Nusa Mandiri, 14(1), 83-88.

Sugianto, C. A. (2015). Penerapan Teknik Data Mining Untuk Menentukan Hasil Seleksi Masuk Sman 1 Cibeber Untuk Siswa Baru Menggunakan Decision Tree. Tedc, 9, 39-43.

Wu, \& Kumar. (2009). The Top Ten Algorithms in Data Mining. USA: CRC Press.

Xu, T., Peng, Q., \& Cheng, Y. (2012). Identifying the semantic orientation of terms using S-HAL for sentiment analysis. Knowledge-Based Syst., 35, 279-289. 